\title{
Characterizing the oceanic ambient noise as recorded by the dense seismo-acoustic Kazakh network
}

\author{
Alexandr Smirnov ${ }^{1,2}$, Marine De Carlo ${ }^{3}$, Alexis Le Pichon ${ }^{3}$, Nikolai M. Shapiro ${ }^{4,5}$, and Sergey Kulichkov ${ }^{6}$ \\ ${ }^{1}$ Institute of Geophysical Research, National Nuclear Center, Almaty, 050020, Kazakhstan \\ ${ }^{2}$ Institut de Physique du Globe de Paris, Sorbonne Paris Cité, 75005 Paris, France \\ ${ }^{3}$ CEA, DAM, DIF, 91297 Arpajon, France \\ ${ }^{4}$ Institut de Sciences de la Terre, Université Grenoble Alpes, CNRS (UMR5275), Grenoble, France \\ ${ }^{5}$ Schmidt Institute of Physics of the Earth, Russian Academy of Sciences, Moscow, 123242, Russia \\ ${ }^{6}$ A.M. Obukhov Institute of Atmospheric Physics, Russian Academy of Sciences, Moscow, 119017, Russia
}

Correspondence: Alexandr Smirnov (smirnov@ipgp.fr)

Received: 22 January 2020 - Discussion started: 3 March 2020

Revised: 12 January 2021 - Accepted: 13 January 2021 - Published: 25 February 2021

\begin{abstract}
In this study, the dense seismo-acoustic network of the Institute of Geophysical Research (IGR), National Nuclear Centre of the Republic of Kazakhstan, is used to characterize the global ocean ambient noise. As the monitoring facilities are collocated, this allows for a joint seismo-acoustic analysis of oceanic ambient noise. Infrasonic and seismic data are processed using a correlation-based method to characterize the temporal variability of microbarom and microseism signals from 2014 to 2017. The measurements are compared with microbarom and microseism source model output that are distributed by the French Research Institute for Exploitation of the Sea (IFREMER). The microbarom attenuation is calculated using a semi-empirical propagation law in a range-independent atmosphere. The attenuation of microseisms is calculated taking into account seismic attenuation and bathymetry effect. Comparisons between the observed and predicted infrasonic and seismic signals confirm a common source mechanism for both microbaroms and microseisms. Multi-year and intra-seasonal parameter variations are analyzed, revealing the strong influence of longrange atmospheric propagation on microbarom predictions. In winter, dominating sources of microbaroms are located in the North Atlantic and in the North Pacific during sudden stratospheric warming events, while signals observed in summer could originate from sources located in the Southern Hemisphere; however, additional analyses are required to consolidate this hypothesis. These results reveal the strengths and weaknesses of seismic and acoustic methods and lead to
\end{abstract}

the conclusion that a fusion of two techniques brought the investigation to a new level of findings. Summarized findings also provide a perspective for a better description of the source (localization, intensity, spectral distribution) and bonding mechanisms of the ocean-atmosphere-land interfaces.

\section{Introduction}

Since the original research of Bertelli (1872), many investigations have confirmed a close connection between microseisms and disturbed ocean weather conditions (LonguetHiggins, 1950). The primary microseism peak (around $0.07 \mathrm{~Hz}$ ) is generated when ocean waves reach shallow water near the coast and interact with the sloping seafloor (Hasselmann, 1963). The secondary peak of microseisms (between 0.1 and $0.2 \mathrm{~Hz}$ ) is generated by the interaction of ocean waves of similar frequencies traveling in opposite directions (Longuet-Higgins, 1950). Longuet-Higgins' theory explains how counter-propagating ocean waves can generate propagating acoustic waves and create secondary microseisms by exciting the sea floor. Hasselmann $(1963,1966)$ generalized Longuet-Higgins' theory to random waves by investigating non-linear forcing of acoustic waves.

Microseism modeling was introduced by Kedar et al. (2008). The good correlation between the observed microseism amplitudes and their predicted values was shown 
(Shapiro, 2005; Shapiro and Campillo, 2004; Stehly et al., 2006; Stutzmann et al., 2012; Weaver, 2005). The different patterns between microseismic body and surface waves, resulting from the amplification of ocean wave-induced pressure perturbation and seismic attenuation, have been studied with implications for seismic imaging and climate studies (Obrebski et al., 2013). Coastal reflections also play an important role in the generation of microseisms, but modeling ocean wave reflections off the coast still remains a major source of model uncertainty (Ardhuin et al., 2013a). Ardhuin and Herbers (2013b) developed a numerical model based on Longuet-Higgins-Hasselmann's theory for the generation of Rayleigh waves, by considering an equivalent pressure source at the undisturbed ocean surface.

Inaudible low-frequency sound, known as infrasound waves, propagates through the atmosphere for distances of thousands of kilometers without substantial loss of energy. Below $1 \mathrm{~Hz}$, infrasound has been observed since the early nineteenth century at different locations distributed around the globe. Gutenberg (1953) first pointed out the relation between microseisms, meteorological conditions, ocean waves, and microbaroms. Donn and Naini (1973) suggested a common source mechanism of microbaroms and microseisms from the same ocean storms demonstrating that the only mechanism capable of transmitting energy into both the atmosphere and the sea bottom is associated with surface wave propagation.

There is a significant difference between microseisms and microbaroms. While propagation paths for microseisms can be either along the Earth's surface as Rayleigh waves, or through the Earth as body waves (Gerstoft et al., 2008), microbarom observations are typically along propagation paths that have undergone multiple bounces on the Earth's surface. As for microseisms, microbaroms are not impulsive signals but quasi-monochromatic sequences of permanent waves (Olson and Szuberla, 2005); therefore, it is not possible to detect their onset and identify their propagation paths. However, these signals are well detected using standard array processing techniques, such as beamforming methods (Capon, 1972; Haubrich and McCamy, 1969; Toksöz and Lacoss, 1968). Several studies demonstrated the efficiency of beam-forming approaches (e.g., Evers and Haak, 2001), or correlation-based methods (e.g., Garcès, 2004; Landès et al., 2012), to detect and characterize microbarom signals globally. Posmentier (1967) started developing a theory of microbaroms based on the LonguetHiggins' theory. A microbarom source model was first developed by Brekhovskikh (1960), later extended by Waxler and Gilbert (2006), Waxler et al. (2007), and more recently extended by de Carlo (2020).

Losses along the propagation path control the ability to observe microbaroms. Thus, in order to accurately assess the microbarom source intensity, it is necessary to take into account a realistic description of the middle atmosphere. Several studies have been conducted to characterize the ambi- ent infrasound noise. Smets et al. (2014) compared microbarom observations with predicted values to study the life cycle of sudden stratospheric warming (SSW). Landès et al. (2014) compared the modeled source region with microbarom observations at operational stations of the International Monitoring System (IMS). A first-order agreement between the observed and modeled trends of microbarom backazimuth was shown. Le Pichon et al. (2015) compared observations and modeling over a 7 -month period to assess middle atmospheric wind and temperature models distributed by the European Centre for Medium-Range Weather Forecasts (ECMWF). It was shown that infrasound measurements can provide additional integrated information about the structure of the stratosphere where data coverage is sparse. More recently, Hupe at al. (2018) showed a first-order agreement between the modeled and observed microbarom back-azimuth and amplitude in the North Atlantic.

In this paper, we develop a synergetic approach to better constrain microbarom source regions and evaluate propagation effects. To this end, we apply the method developed by Hupe et al. (2018) to the dense Kazakhstani seismo-acoustic network. The considered network is operated by the Institute of Geophysical Research (IGR) of the National Nuclear Centre of the Republic of Kazakhstan. It includes both seismic and infrasound arrays. Since the pioneering work of Donn and Naini (1973), to our knowledge, this study is the first multi-year comparisons between observed and modeled ambient noise at collocated seismo-acoustic arrays. In the first part, we have presented the observation network and the methods used. In the second part, the processing and modeling results of microseism and microbarom signals recorded by the IGR seismo-acoustic network from 2014 to 2017 are shown. In the last part, comparisons between the observed and modeled microbaroms and microseism are discussed.

\section{Observation network and methods}

\subsection{Observation network}

\subsubsection{Infrasound array network}

The Kazakhstani seismo-acoustic network (KNDC, 2019) contains five seismic and three infrasound arrays (Fig. 1). The signal correlation in such a dense network is significantly higher compared to sparser networks like the IMS. The infrasound network consists of the IMS station IS31 located in northwestern Kazakhstan $(2.1 \mathrm{~km}$ aperture, 8 elements) and two national arrays of $1 \mathrm{~km}$ aperture: KURIS (4 elements) near Kurchatov and MKIAR (9 elements) near the village of Makanchi (Belyashov et al., 2013). KURIS and MKIAR have been operating since 2010 and 2016, respectively. Microbarometers MB2000 and MB2005 are used at IS31 and KURIS, and Chaparral Physics Model 25 microbarometers are installed at MKIAR. All arrays are equipped 


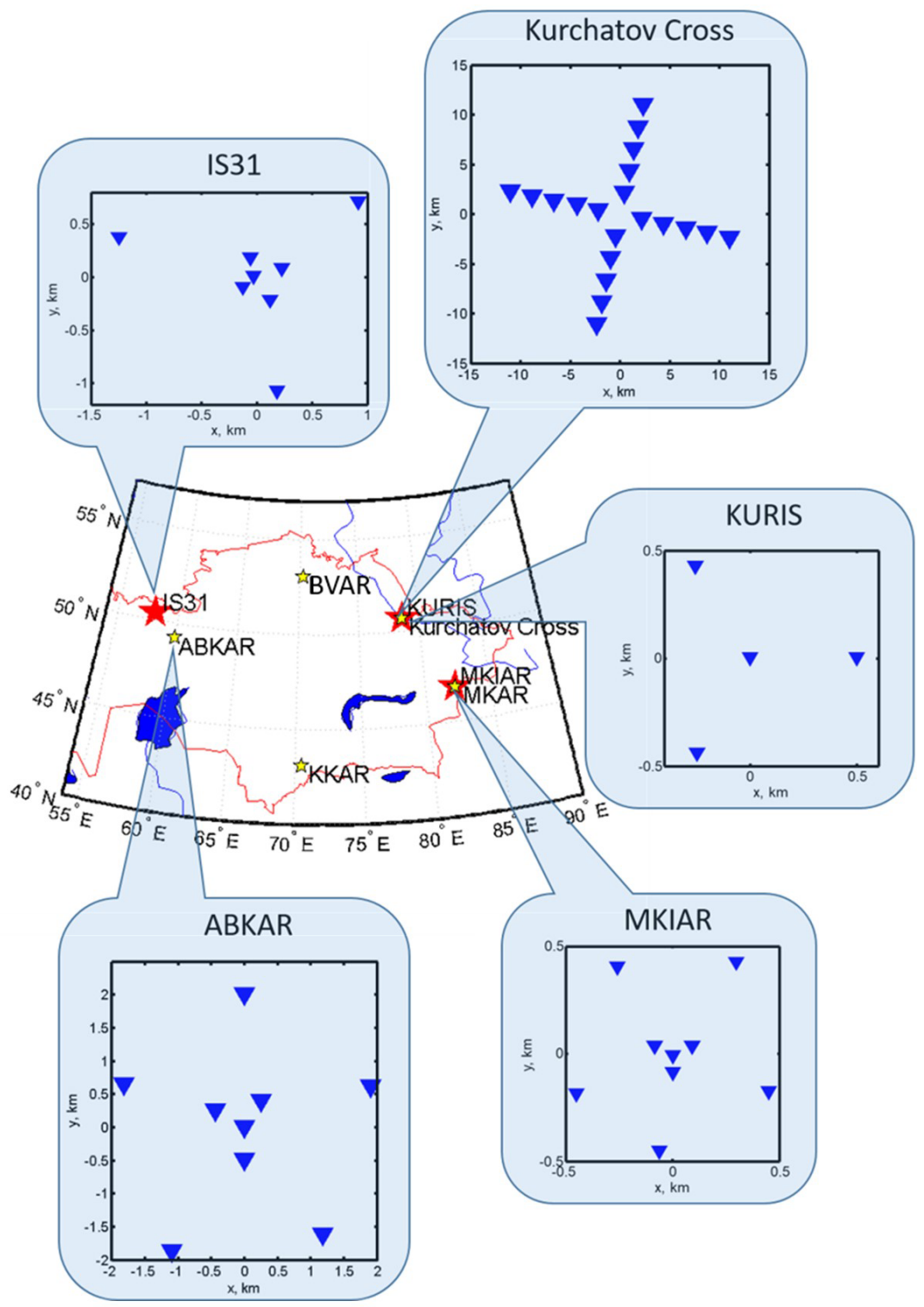

Figure 1. IGR monitoring network. Yellow and red stars are seismic and infrasound arrays, respectively. Seismic and infrasound arrays are collocated at Kurchatov (Kurchatov Cross/KURIS) and Makanchi (MKAR/MKIAR). IS31 infrasound and ABKAR seismic arrays are located $\sim 200 \mathrm{~km}$ apart. The inset graphs show the array configurations. The configurations for KKAR and MKAR seismic arrays are not shown as they are similar to ABKAR's one.

with a 24-bit digitizer with a sampling frequency of $20 \mathrm{~Hz}$ at IS31 and KURIS and $40 \mathrm{~Hz}$ at MKIAR. Data logger parameters are listed in Table A1 (Appendix A). All stations are equipped with a 96-port wind noise-reducing system with pipe rosettes, except L1, L2, L3, and L4 elements at IS31 which are connected to 144 inlet ports (Marty, 2019). The frequency responses of the microbarometers are shown in Fig. A1a and b. By associating infrasound observables over the network, both natural and anthropogenic infrasound sources can be detected and characterized (Smirnov, 2015; Smirnov et al., 2010, 2018).

\subsubsection{Seismic array network}

The seismic network consists of a Kurchatov Cross array and MKAR that are part of the IMS network, as well as ABKAR and KKAR arrays which are part of the Air Force Technical Applications Centre (AFTAC, USA) network (Fig. 1 and Table 1). The Kurchatov Cross array consists of 20 Guralp CMG-3V sensors with an aperture of $\sim 22.5 \mathrm{~km}$ (Fig. 1). ABKAR, BVAR, KKAR, and MKAR arrays consist of nine elements with an aperture of $\sim 5 \mathrm{~km}$. These arrays are equipped with Geotech Instruments GS21 short-period vertical sensors with a flat response for frequencies above $1 \mathrm{~Hz}$. 
The frequency response of the sensors at MKAR, ABKAR, and KKAR is not flat in the $0.1-0.3 \mathrm{~Hz}$ band; however, as the response information is given, one can correct for the drop in amplitude; the phase shift difference between instruments that are part of the same array is assumed negligible. Figure A1c and d show the frequency response of GS-21 and CMG-3V sensors between 0.1 and $0.4 \mathrm{~Hz}$. All arrays are equipped with 24-bit digitizers, sampling data at $40 \mathrm{~Hz}$. Surface waves from the ocean storms are well recorded by broadband seismometers. Body waves are also registered by GS21 short period sensors. Although in the frequency band of interest the signal attenuation is about $30 \mathrm{~dB}$, all stations detect microseisms due to their large amplitude above the background noise.

A peculiarity of the network is that infrasound and seismic arrays are collocated at two sites (KURIS and Kurchatov Cross; MKIAR and MKAR), or installed relatively close to each other (IS31 and ABKAR are $220 \mathrm{~km}$ apart; Fig. 1). Figure B1 shows typical power spectral density (PSD) of the ambient noise at infrasound and seismic arrays, and at collocated Kurchatov cross seismic and KURIS infrasound arrays. PSD calculation was carried out using a $1 \mathrm{~h}$ time window during calm periods in October, December, and July. The microbarom peak is more pronounced in October and December. In summer, this peak is only visible at IS31. As opposed to the infrasound noise, the seismic noise spectra exhibit the microseismic peak in both seasons with an overall noise level in October approximately $10 \mathrm{~dB}$ higher than in July.

\subsection{Processing method}

Microseisms are detected using the progressive multichannel correlation (PMCC) method (Cansi, 1995; Cansi and Klinger, 1997; Smirnov et al., 2010) in 10 linearly spaced frequency bands between 0.05 and $0.4 \mathrm{~Hz}$. A fixed time window length of $200 \mathrm{~s}$ is used for each band. For the infrasound processing, the frequency band is broadened to $0.01-4 \mathrm{~Hz}$ using 15 logarithmically scaled sub-bands, and a time window length varying from 30 to $200 \mathrm{~s}$ (Matoza et al., 2013). Such a setting allows computationally efficient broadband processing and accurate estimates of frequency-dependent wave parameters useful for source separation and characterization. In the microbarom frequency range covering the $0.1-0.6 \mathrm{~Hz}$ interval, wave parameters can be detailed in six different frequency bands (Ceranna et al., 2019).

It is important to take into account uncertainties in azimuth and apparent velocity estimations identified in microbarom studies. The uncertainties of the estimated wave parameters of microseisms can be large due to the relatively small aperture of the arrays. Uncertainties in wave parameter estimates are calculated considering the array geometry of the abovementioned infrasound and seismic arrays, assuming perfectly coherent signals and time delay errors bounded by twice the sampling period (Szuberla and Olson, 2004) (Table 1). For the infrasound arrays, the horizontal speed is set to
$0.34 \mathrm{~km} \mathrm{~s}^{-1}$. For the seismic arrays, a typical Rayleigh wave speed of $3 \mathrm{~km} \mathrm{~s}^{-1}$ is chosen. The uncertainties for the seismic arrays are significantly higher for the body waves due to higher velocities. It should be noted that these errors are optimistic as the estimation does not take into account the siteand time-dependent signal-to-noise ratio.

\subsection{Source modeling}

The microseism source model used (IFREMER, 2018), referred to as "p21", is calculated from the wave-action WAVEWATCH III model (WW3) developed by the National Oceanic and Atmospheric Administration (NOAA). While the bathymetry strongly affects the source intensity in microseism modeling (Ardhuin et al., 2011; Ardhuin and Herbers, 2013b; Kedar et al., 2008), a recent modeling study by De Carlo (2020) suggests that bathymetry has negligible impact on microbarom source strength in contrast to predictions from the model by Waxler et al. (2007). In this study, the source term for microseisms ("p2l") which does not include coupling with the bathymetry is taken as a proxy to model microbaroms. While microseisms propagate through the static structure of the solid Earth, long-range microbarom propagation is controlled by the strong spatiotemporal variability of the temperature and wind structure of the atmosphere. Therefore, the geometrical spreading and seismic attenuation are the main effects to account for microseism modeling (e.g., Kanamori and Given, 1981; Stutzmann et al., 2012), while the dynamical properties of the middle atmosphere should be taken into account for microbarom modeling.

\subsubsection{Microbarom source modeling}

As previously stated, both microseisms and microbaroms originate from second-order non-linear wave interactions. Their source term can be written as a function of the secondorder equivalent surface pressure $F_{\mathrm{p}}\left(f_{2}=2 f\right)$ (Hasselmann, 1963; Ardhuin et al., 2011):

$F_{\mathrm{p}}\left(f_{2}=2 f\right)=\frac{1}{2} \rho_{\mathrm{w}}^{2} g f_{2} H(f)$,

where $p_{\mathrm{w}}$ is the water density, $g$ is the gravitational acceleration, and $f_{2}$ is the microseism and microbarom frequency. The Hasselmann integral $H(f)=$ $\int_{0}^{2 \pi} E(f, \theta) E(f, \theta+\pi) d \theta$ (Hasselmann, 1963) represents the number of opposite propagative wave interactions, with $(E(f, \theta)$ the directional spectrum of waves. The IFREMER distribution of the wave action model WAVEWATCH III ${ }^{\circledR}$ (WW3 Development Group, 2016; ftp://ftp.ifremer.fr/ ifremer/ww3/HINDCAST/SISMO, last access: 4 May 2020) includes the calculation of $F_{\mathrm{p}}\left(f_{2}=2 f\right)$ with a $0.5^{\circ} \times 0.5^{\circ}$ spatial resolution and $3 \mathrm{~h}$ temporal resolution.

Longuet-Higgins (1950) showed that these pressure fluctuations in the water do not attenuate with depth but are transmitted to the ocean bottom as acoustic waves. Depending 
Table 1. Uncertainties of azimuth and apparent velocity estimates.

\begin{tabular}{lrrrrrrr}
\hline Parameter & IS31 & KURIS & MKIAR & ABKAR & KKAR & MKAR & Kurchatov Cross \\
\hline $\begin{array}{l}\text { Horizontal velocity, } \\
\mathrm{m} \mathrm{s}^{-1}\end{array}$ & 340 & 340 & 340 & 3000 & 3000 & 3000 & 3000 \\
\hline$\delta \Theta\left(^{\circ}\right)$ & $0.55-0.74$ & $2.05-2.34$ & $0.58-0.67$ & $4.89-5.64$ & $5.14-6.30$ & $4.55-6.84$ & $0.48-0.49$ \\
\hline$\delta \mathrm{V}\left(\mathrm{m} \mathrm{s}^{-1}\right)$ & $3.8-4.4$ & $12-14$ & $3.5-3.9$ & $250-290$ & $270-330$ & $220-380$ & $25-26$ \\
\hline
\end{tabular}

on the ratio between the wavelength of the acoustic waves and the ocean depth, resonance effects can occur leading to a modulation of the pressure fluctuations at the sea floor (Stutzmann et al., 2012). Therefore, microseisms are strongly affected by the bathymetry (Ardhuin et al., 2011; Ardhuin and Herbers, 2013b; Kedar et al., 2008). The corresponding seismic source power spectral density at the ocean bottom is as follows (Longuet-Higgins, 1950; Eq. 184):

$S_{\mathrm{DF}}\left(f_{\mathrm{s}}=f_{2}\right)=\frac{2 \pi f_{\mathrm{s}}}{\rho_{\mathrm{s}}^{2} \beta^{5}}\left[\sum_{m=1}^{m=N} c_{\mathrm{m}}^{2}\right] F_{\mathrm{p}}\left(f_{2}=2 f\right)$,

where $\mathrm{S}_{\mathrm{DF}}$ is in $\mathrm{m} \mathrm{Hz} z^{-1}, \rho_{\mathrm{s}}$ and $\beta$ are respectively the density and $\mathrm{S}$-wave velocity in the crust, and the coefficient $c_{\mathrm{m}}$ corresponds to the compressible ocean amplification factor. $c_{\mathrm{m}}$ is a non-dimensional number varying between 0 and 1 as a function of the ratio $2 \pi f 2 h / \beta$, where $h$ is the water depth. In this study, the crustal density $\rho_{\mathrm{s}}=2600 \mathrm{~kg} \mathrm{~m}^{-3}$ and the $\mathrm{S}$-wave velocity $\beta=2800 \mathrm{~m} \mathrm{~s}^{-1}$. The microbarom source term developed by De Carlo (2020) is essentially a scaled version of the second-order equivalent surface pressure $F_{\mathrm{p}}\left(f_{2}=2 f\right)$, which serves as proxy of microbarom source term.

\subsubsection{Microbaroms propagation}

For the propagation modeling, we use a semi-empirical frequency-dependent attenuation relation derived from massive parabolic equation simulations (Le Pichon et al., 2012). Atmospheric specifications are extracted at the station from the high-resolution forecast (HRES) that is part of ECMWF's Integrated Forecast System (IFS) cycle 38r2 (http://www. ecmwf.int, last access: 15 February 2021) and are assumed to be constant along the propagation path. This approach, already used by De Carlo et al. (2018) and Hupe et al. (2018) to model microbaroms generated in the Northern Hemisphere, can predict the observed back-azimuths with an error less than $\sim 10^{\circ}$. The correlation coefficient between the observed and predicted seasonal patterns is calculated following metrics elaborated by Landès et al. (2014). The correlation is evaluated for the back-azimuths and amplitudes. Two different metrics are derived: (i) $S_{\text {corr_Az, }}$ which defines the correlation between the observed $\left(N_{\text {obs }}\right)$ and predicted $\left(N_{\text {pred }}\right)$ marginal detection number in the direction $\theta_{\text {Amax }}$ versus time $(t)$

$S_{\text {corr_Az }}=C_{\text {corr }}\left[N_{\text {obs }}\left(\theta_{\text {Amax }, t}\right), N_{\text {pred }}\left(\theta_{\text {Amax }, t}\right)\right]$,

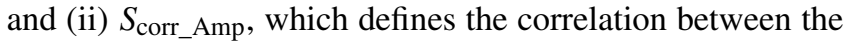
predicted and observed amplitude $A_{\max }$,

$S_{\text {corr_Amp }}=C_{\text {corr }}\left[N_{\text {obs }}\left(A_{\max , t}\right), N_{\text {pred }}\left(A_{\max , t}\right)\right]$.

\section{Results}

\subsection{Processing results}

Signals from the ocean storms are extracted from detections at all IGR infrasound and seismic arrays, and filtered between 0.1 and $0.4 \mathrm{~Hz}$. Diagrams in this section show the back-azimuths of the signals as a function of time. Distributions of the maximum amplitudes are included as well. The amplitude maxima are averaged over a $6 \mathrm{~h}$ time window for the entire period from 2014 to 2017.

\subsubsection{Microbaroms}

Figure 2 shows the temporal variation of the dominant microbarom signals at IS31, KURIS, and MKIAR. The graphs show pronounced seasonal variations for both back-azimuths and amplitudes. The largest amplitudes at IS31 are observed during the winter months with a dominant period ranging from 3.5 to $5.5 \mathrm{~s}$ (Fig. C1), when signals with backazimuths of $320 \pm 20^{\circ}$ prevail (Fig. $2 \mathrm{a}-\mathrm{b}$ ). A few detections with back-azimuths of $35 \pm 15^{\circ}$ are also detected. In winter, microbarom amplitudes range from $\sim 0.005$ to $\sim 0.5 \mathrm{~Pa}$, the largest values being observed in winter. During summer months, signals with back-azimuths of $210 \pm 50^{\circ} \mathrm{dom}-$ inate with a period ranging from 4 to $6.5 \mathrm{~s}$ and lower amplitude $(\sim 0.01 \mathrm{~Pa})$, suggesting waves propagating over longer epicentral distances. Figure $2 \mathrm{e}-\mathrm{h}$ show the observations at KURIS. The back-azimuths measured at this station are similar to those recorded at IS31, with slightly higher values in winter $\left(325 \pm 15^{\circ}\right)$ and two clusters in summer at $230 \pm 30^{\circ}$ and $120 \pm 30^{\circ}$. In summer, back-azimuths of $210 \pm 50^{\circ}$ also dominate at IS31, KURIS, and MKIAR. MKIAR started recording microbaroms in August 2016 with cyclical seasonal variations (Fig. 2i-e).

\subsubsection{Microseisms}

Figure $3 a-d$ show the detection results at ABKAR. In addition to the observations, the diagrams represent the simulated 
(a)

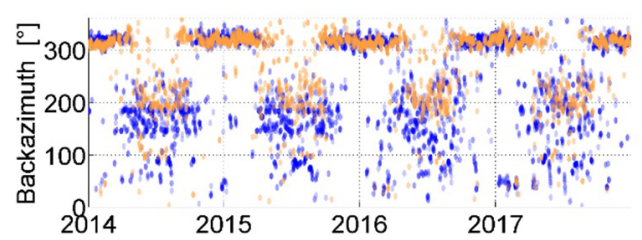

(c)

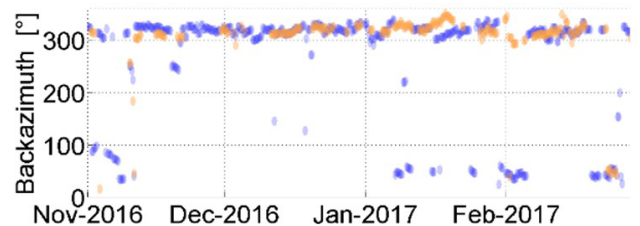

(e)

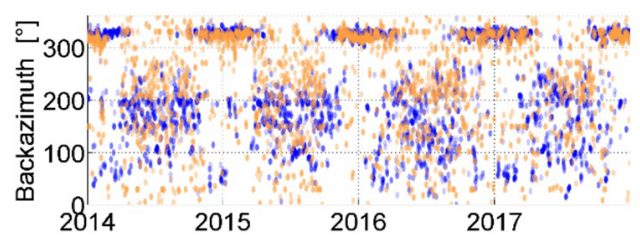

(g)

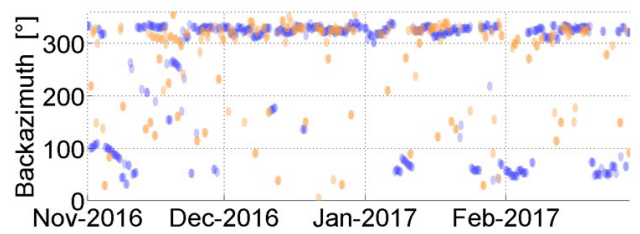

(i)

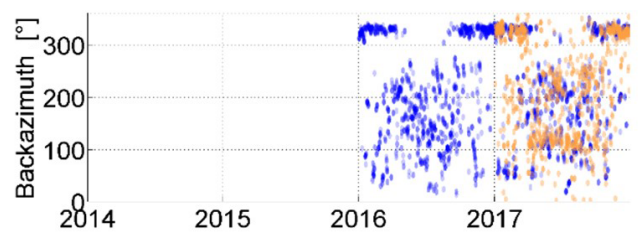

(k)

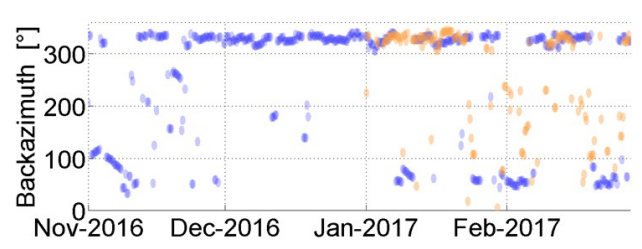

IS31

(b)

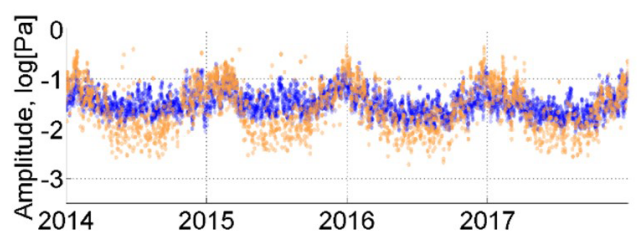

(d)

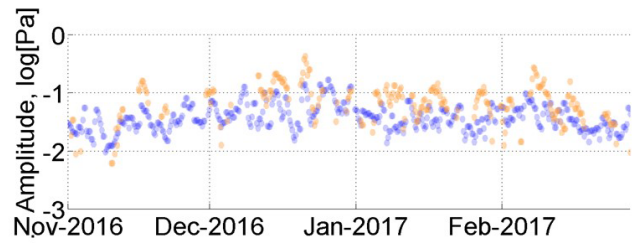

KURIS

(f)

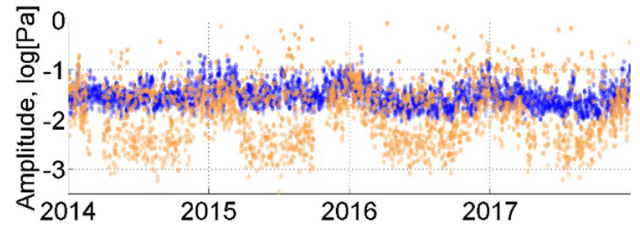

(h)

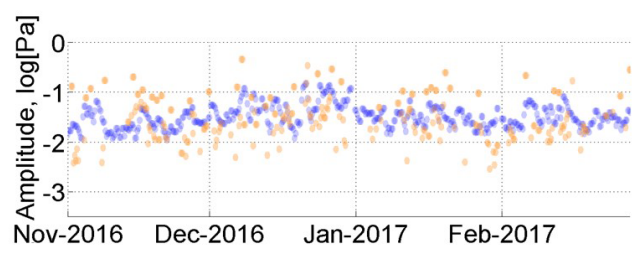

MKIAR

(j)

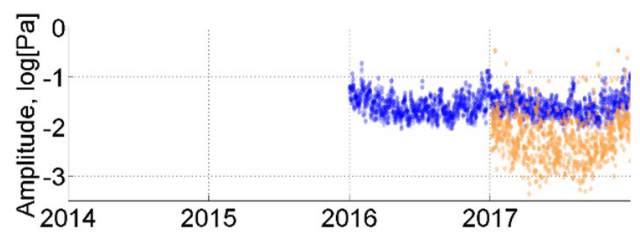

(I)

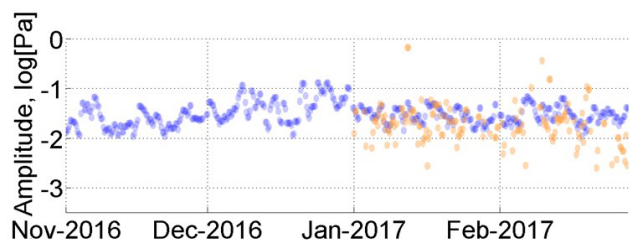

Figure 2. Time variations of observed back-azimuths and amplitudes of microbaroms at IS31 (a-d), KURIS (e-h), and MKIAR (i-l), with a time resolution of $6 \mathrm{~h}$ from 1 January 2014 to 31 December 2017 (orange circles). Blue circles denote simulated values. Details at IS31 (c, d), KURIS (g, h), and MKIAR (k-l).

microseism parameters. The largest amplitudes are observed in winter where detections at $340 \pm 20^{\circ}$ prevail. In summer, signals at $290 \pm 20^{\circ}$ dominate. The amplitudes range from $\sim 250$ to $\sim 10000 \mathrm{~nm} \mathrm{~s}^{-1}$. Figure $3 \mathrm{e}-\mathrm{h}$ show the results at KKAR. Two clusters of detections at $330 \pm 20^{\circ}$ and $5 \pm 5^{\circ}$ are observed in winter, and at $160 \pm 20^{\circ}$ and $190 \pm 15^{\circ}$ in summer.
The seasonal amplitude variation is $\sim 250$ to $\sim 9000 \mathrm{~nm} \mathrm{~s}^{-1}$. Figure $3 \mathrm{i}-1$ show the results at Kurchatov Cross. In winter, back-azimuths of microseisms are $300 \pm 20^{\circ}$. A small number of detections at $50 \pm 50^{\circ}$ is observed in summer. The amplitudes range from 250 to $9000 \mathrm{~nm} \mathrm{~s}^{-1}$, reaching their maximum values in winter. Figure $3 \mathrm{~m}-\mathrm{p}$ show results at MKAR. 
(a)

(c)

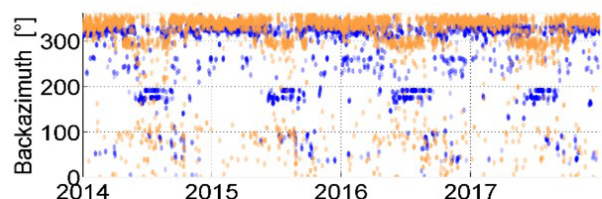

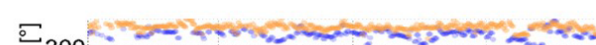

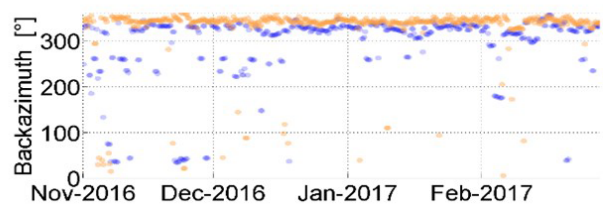

(e)

(g)
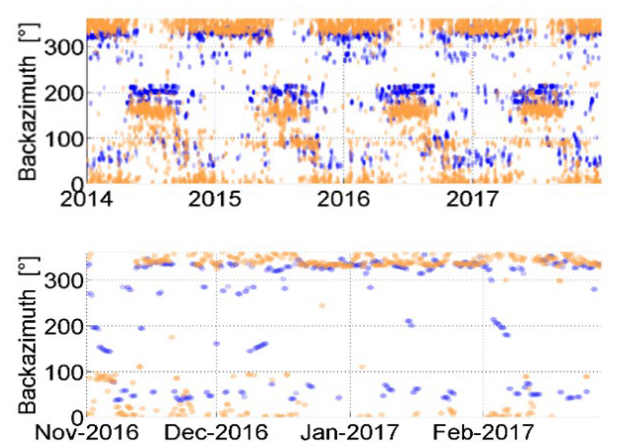

(i)

(k)
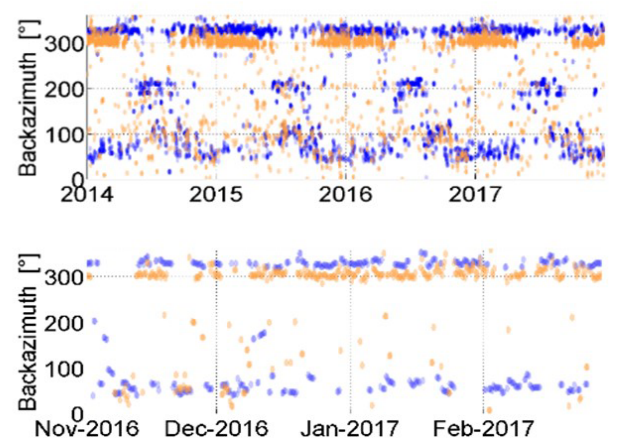

(m)

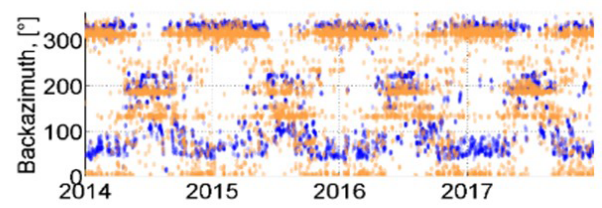

(o)

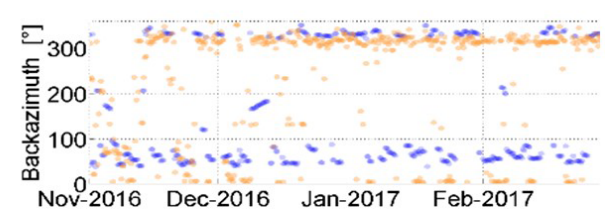

ABKAR

(b)

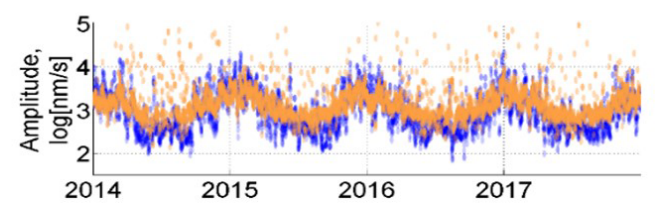

(d)

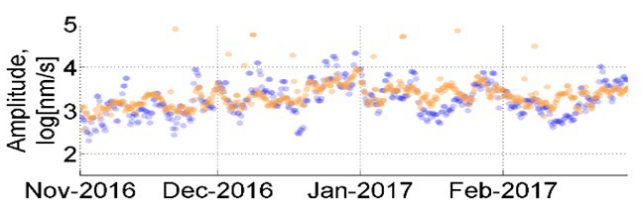

KKAR

(f)

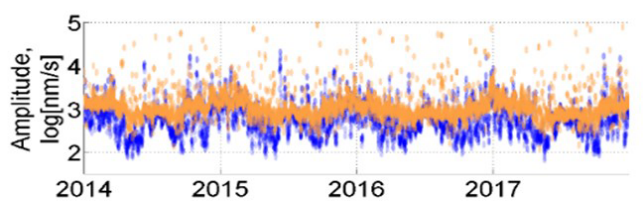

(h)

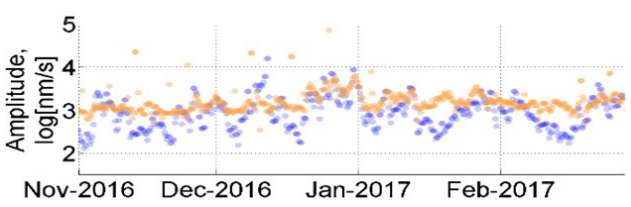

Kurchatov Cross

(j)

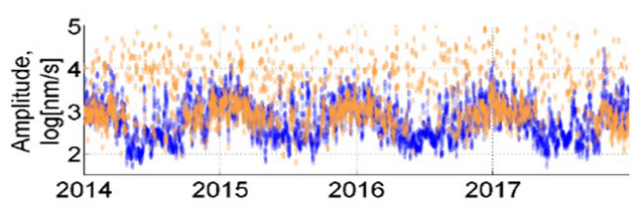

( I)

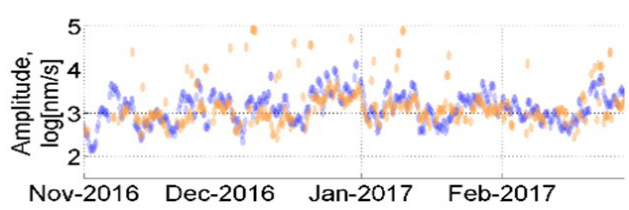

MKAR

(n)

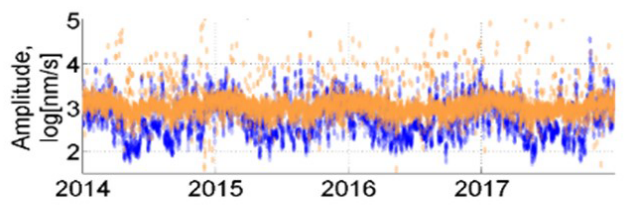

(p)

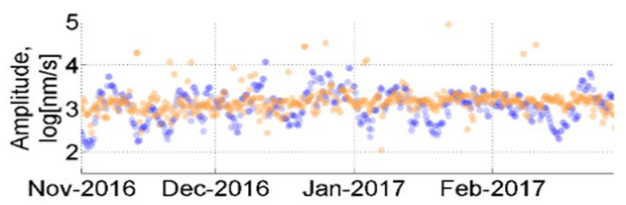

\section{Observations}

Simulations

Figure 3. Same as Fig. 2 at ABKAR (a-d), KKAR (e-h), Kurchatov Cross (i-l), and MKAR (m-p). 
Two clusters at $310 \pm 20^{\circ}$ and $5 \pm 5^{\circ}$ are observed in winter, and at $130 \pm 10^{\circ}$ and $180 \pm 10^{\circ}$ in summer. The seasonal amplitude variation is $\sim 250$ to $\sim 3000 \mathrm{~nm} \mathrm{~s}^{-1}$. The seasonal trend of the microseism amplitudes recorded at all seismic stations is similar, with a maximum observed in winter. At Kurchatov Cross, the small number of detections in summer could be explained by a higher noise level or a loss of signal coherency at this site. The graphs clearly show that the amplitudes vary synchronously even at smaller timescales (Fig. 4). As expected, the maximum amplitudes decrease with increasing distance from the stations to the North Atlantic region (about 10000, 9000, 9000, and $5000 \mathrm{~nm} \mathrm{~s}^{-1}$ for ABKAR, KKAR, Kurchatov Cross, and MKAR, respectively).

\subsection{Modeling results}

The back-azimuths and amplitudes have been predicted at IS31, KURIS, and MKIAR. The distances to the source regions differ essentially from summer to winter. For example, simulations predict three source regions at IS31 in winter. Distances to the two regions in the North Atlantic are around 3500 and $7000 \mathrm{~km}$, and about $7000 \mathrm{~km}$ to the North Pacific. In summer, one source region is located in the Pacific Ocean and two other sources at southern high latitudes are at distances of $\sim 12000 \mathrm{~km}$ and $\sim 18000 \mathrm{~km}$. However, the calculation of attenuation using a range-independent atmospheric model would inevitably lead to great mistakes in such a situation. Figure $2 \mathrm{a}-\mathrm{l}$ compare the observed and predicted arrivals at these stations. In winter, a good agreement is found: IS31 records microbaroms with back-azimuths of $320 \pm 20^{\circ}$ within the predicted range (Fig. 2a-c). A good agreement is also observed at KURIS (Fig. 2o-g) and MKIAR (Fig. 2i-k).

In summer, the agreement in azimuths remains satisfactory at all stations within a range of $\pm 30^{\circ}$. IS31 records microbaroms within $210 \pm 50^{\circ}$ with a slight shift compared with the predicted system $\left(185 \pm 50^{\circ}\right)$. At KURIS, the observed systems $230 \pm 30^{\circ}$ and $130 \pm 30^{\circ}$ are different compared with the predicted ones $\left( \pm 10^{\circ}\right.$ and $\left.160 \pm 10^{\circ}\right)$. At MKIAR, during the summer months, microbaroms are predicted with larger discrepancies $\left( \pm 70^{\circ}\right)$. As the used source model was developed for microseisms (Ardhuin et al., 2011), an empirical scaling factor $(F=1: 2600)$ has been applied to account for the wave coupling effect in the atmosphere, thus allowing qualitative comparisons between the observed and predicted temporal variations of the microbarom amplitudes. Overall, at all stations, there is good agreement between the predicted and observed amplitudes during the winter months (Fig. 2d, h, l), but in summer, the predicted amplitudes are overestimated (Table 2). A first reason is that PMCC cannot detect multiple sources in the same frequency band. A second reason is the limitation of the propagation modeling which considers range-independent atmosphere. It can be noted that the propagation anomaly predicted during the SSW on JanuaryFebruary 2017 is not observed. Wind noise variations at the station, not considered in the simulations, could explain part of these discrepancies.

To summarize, both amplitudes and azimuths of the microbaroms are well predicted in winter as opposed to summer months. Microseism predictions show dominant source regions south of the arrays that are not observed. Quantitative estimations of the prediction quality ( $S_{\text {corr }}$ calculated according to Eqs. 3 and 4) are summarized in Table 2.

\section{Discussion}

Where previous studies analyzed microbarom signals at a single station (Hupe et al., 2018), further investigations are conducted here by considering a multi-year dataset of continuous records collected by the IGR network. Regional features of both microbaroms and microseisms are highlighted. Figure D1a-n in Appendix D show the azimuthal distribution of infrasound detections with maximum amplitudes. Figure D2a-d show similar histograms for seismic stations. One can distinguish seasonal trends for both infrasonic and seismic observations. In winter, microbaroms and microseisms are detected from the northern and northwestern directions. In summer, southern, southwestern, and southeastern directions dominate; signals from the northwestern direction are also recorded at ABKAR, KKAR, and MKAR. Azimuths differ from one station to another depending on the strongest microbarom and microseism source regions relative to the station locations. Observations and simulations show large temporal variations in the dominating microbarom source regions explained by the seasonal reversals of the prevailing stratospheric winds, which in turn cause the migration of the storm activity area to the winter hemisphere. The histograms of the azimuthal distribution of microbaroms (Fig. D1) clearly show the dominating direction of arrivals in winter with prevailing directions ranging from 270 to $350^{\circ}$. The predicted azimuths are in good agreement with the observed ones as shown by Figs. 2c, g, and k and D1 and Table 2. In winter, microseism observations exhibit a similar pattern with a larger spread $\left(250-360^{\circ}\right)$, and an additional peak $\left(0-20^{\circ}\right)$ at KKAR and MKAR (Fig. D1df). These peaks are explained by North Pacific microseism source regions.

In winter, microseisms exhibit similar trends with some differences as shown by Fig. 3c, g, k, and o. The dominant directions are comparable with a larger spreading: from 250 to $360^{\circ}$ and from 0 to $20^{\circ}$. At KKAR and MKAR, two peaks are noted in the histograms, with a second peak at $0-20^{\circ}$. These peaks are explained by North Pacific microseisms. In summer, microbaroms are predicted mainly from the southern direction $\left(180-200^{\circ}\right)$. Such a peak is observed only at IS31 and MKIAR (Fig. D1c), although there is a large spreading in the predictions $\left(45-225^{\circ}\right)$. The closest peak observed at KURIS and MKIAR is shifted northwards by $\sim 50^{\circ}$. The dominant back-azimuths are close to $90^{\circ}$. In winter, signals from ocean 
(a)

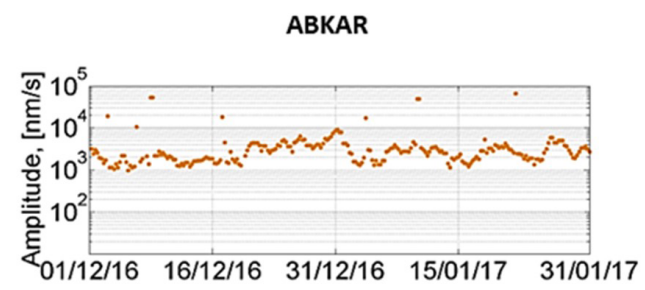

Kurchatov Cross

(c)

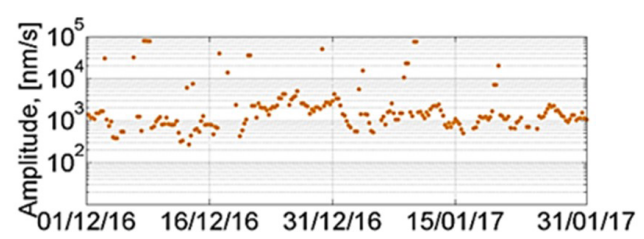

(b)

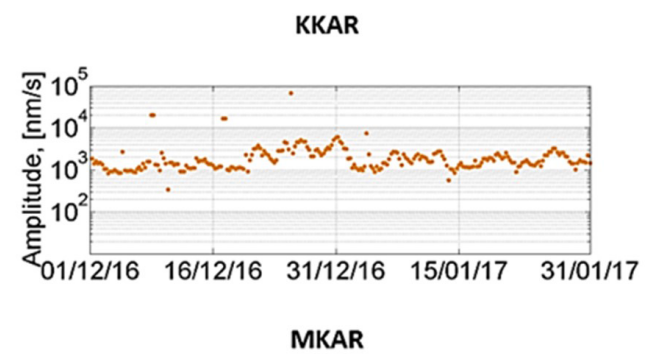

(d)

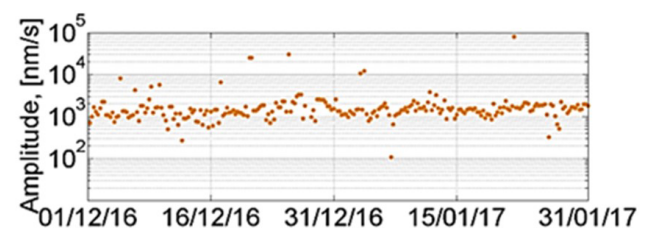

Figure 4. Dominant amplitude of microseisms in the 0.1-0.4 Hz band detected at ABKAR (a), KKAR (b), Kurchatov Cross (c), and MKAR (d) arrays from 1 December 2016 to 31 January 2017.

Table 2. Estimations of the prediction quality for microbarom amplitudes and azimuths.

\begin{tabular}{|c|c|c|c|c|c|c|c|c|c|}
\hline Station & $\begin{array}{l}\text { Long-term } \\
\text { observation period }\end{array}$ & $S_{\text {corr_Az }}$ & $S_{\text {corr_Amp }}$ & $\begin{array}{l}\text { Observation } \\
\text { period on winter }\end{array}$ & $S_{\text {corr_Az }}$ & $S_{\text {corr_Amp }}$ & $\begin{array}{l}\text { Observation } \\
\text { period on summer }\end{array}$ & $S_{\text {corr_Az }}$ & $S_{\text {corr_Amp }}$ \\
\hline IS31 & 2014-2017 & 0.61 & 0.39 & $\begin{array}{l}\text { December 2016- } \\
\text { February } 2017\end{array}$ & 0.76 & 0.53 & June-August 2017 & 0.44 & 0.26 \\
\hline KURIS & 2014-2017 & 0.52 & 0.23 & $\begin{array}{l}\text { December 2016- } \\
\text { February } 2017\end{array}$ & 0.82 & 0.58 & June-August 2017 & 0.16 & 0.18 \\
\hline MKIAR & $\begin{array}{l}\text { September 2016- } \\
\text { December } 2017\end{array}$ & 0.62 & 0.5 & $\begin{array}{l}\text { December 2016- } \\
\text { February } 2017\end{array}$ & 0.82 & 0.66 & June-August 2017 & 0.34 & 0.39 \\
\hline
\end{tabular}

storms in the North Atlantic dominate at all stations. This is supported by microbarom and microseism simulations. Microbarom sources recorded by the Kazakh network in summer are not fully characterized. The cross-bearing location considering detections at IS31, KURIS, and MKIAR yields a hotspot located southwest of South America (Fig. C2). Since the localization does not include the crosswind effect, the true location may differ significantly from the preliminary estimation. Furthermore, the fact that a signal should pass a considerable portion of the way upwind would prejudice the likelihood of its registration. However, this preliminary location is consistent with the relatively low amplitude values and larger periods in summer than in winter (Fig. C1). Additional studies using more realistic propagation modeling are required to confirm this hypothesis. In this study, the method used to predict the attenuation assumes a range independent atmosphere along the propagation paths. Such an approach cannot be applied to situations involving long propagation ranges where significant along-path variability of wind and temperature profiles may occur (especially when sources and network are located in different hemispheres). Using historical IGR datasets, the spatiotemporal variability of microbarom signals due to changes in the source location and the structure of the atmospheric waveguides can be stud- ied. There is a clear seasonal trend in both directions and amplitudes of microbaroms and microseisms (Fig. 2). Moreover, microseism amplitudes synchronously vary at all stations (Fig. 4). A good agreement between observations and simulations is found for the azimuths. The bathymetry effect plays an important role when calculating the microseism source intensity. As already shown by Evers and Siegmund (2009) and Smets and Evers (2014), SSW events can be inferred from the observed spatiotemporal variations of microbarom parameters. Such observations are noted at IS31 where microbaroms in early and late February 2017 are shifted to easterly directions $\left(\sim 40^{\circ}\right)$, which is consistent with the simulated source regions in the North Pacific (Fig. 2a, c). As noted at IS31, KURIS also recorded signals with back-azimuths of $\sim 40^{\circ}$ in late January 2017 (Fig. 2e, g). Similarly, signals from $\sim 100^{\circ}$ were also recorded during the $2017 \mathrm{SSW}$ event at MKIAR. However, the observed back-azimuths differ from the predicted ones $\left(\sim 60^{\circ}\right)$. It is likely that this station recorded signals from other regions over the Pacific Ocean, which are not described by the ocean wave model used. These findings are consistent with comparisons between the observed and modeled microbaroms carried out by Landès et al. (2014) at IS31. This study shows that modeling 
well describes microbarom sources in the North Atlantic in winter, while signals in summer are poorly explained.

Comparing microbaroms and microseisms at collocated sites highlights similar features. Figure $5 \mathrm{a}-\mathrm{d}$ present the observed back-azimuths and signal amplitudes from 1 January 2014 to 31 December 2017 at ABKAR and IS31, located $230 \mathrm{~km}$ apart. Figure $5 \mathrm{e}-\mathrm{h}$ show the detection results for the collocated Kurchatov Cross and KURIS arrays. The comparison of the bulletins in Fig. 5 shows similar seasonal patterns:

- North Atlantic microseisms and microbaroms prevail in winter. Back-azimuths of $300-360^{\circ}$ are clearly visible in Fig. 5a, b, e, and g.

- Amplitudes of North Atlantic microbaroms and microseisms observed in winter exceed those observed in summer, as shown in Fig. 5b, d, f, and h.

Specific features are identified:

- Arrays record North Atlantic microseisms more steadily than microbaroms from that region (Fig. 5).

- The range of back-azimuths for North Atlantic microseisms is larger than the ones of microbaroms at ABKAR and MKAR as shown by Fig. 5a, b, e, and g. In winter, at ABKAR, signals with back-azimuth of $\sim 310^{\circ}$ are predicted, while the observed signals dominate at $\sim 340^{\circ}$. In summer, the signals predicted around $\sim 180^{\circ}$ are not observed (Fig. 3a). Such deviations in surface wave back-azimuths were earlier identified during teleseismic events observation at AlpArray (Kolínský and Bokelmann, 2019). To substantiate this hypothesis, source-specific static corrections (SSSCs) are required. However, the SSSC evaluation would require long-term instrumental observations, which is out of the scope of the present study.

- In summer, no correlation is found in the prevailing directions of microseism and microbarom arrivals at collocated arrays.

This study aims at characterizing the oceanic ambient noise using infrasound and seismic methods. The results show that exploiting the synergy between seismic and infrasound ambient noise observations is valuable to (i) better constrain the source strength using seismic records as microseisms propagate through the static structure of the Earth, while microbaroms travel through a highly variable atmosphere both in space in time, (ii) improve the detectability of ocean-wave interaction and location accuracy as microbarom wave parameters are less affected by heterogeneities in the propagation medium, and (iii) improve the physical description of seismo-acoustic energy partitioning at the ocean-atmosphere interface. While dominant features of microseisms and microbaroms are successfully recovered, some limitations of the proposed approach are identified.
One limitation is the inability of the PMCC method to detect signals from several sources overlapping in the same frequency band. Another methodological shortcoming is the range-independent atmosphere considered for propagation simulations. Such an approach cannot be applied to situations involving long propagation ranges where significant along-path variability of wind and temperature profiles may occur; especially when sources and network are located in different hemispheres. Additional studies are also required to further evaluate whether the bathymetry effect could explain discrepancies between the observed microbarom and microseism signals (Longuet-Higgins, 1950; Stutzmann et al., 2012; De Carlo, 2020).

\section{Conclusions}

The IGR seismo-acoustic network is much denser than the global IMS infrasound network. Analyzing multi-year archives of continuous recordings provides a detailed picture of the spatial and temporal variability of the seismic and infrasound ambient noise originating from two hemispheres. In winter, the most intense oceanic storms are modeled in the North Atlantic, and their signature prevails on infrasound and seismic records. During minor SSW events, bi-directional conditions may occur which may have strong impacts on the retrieved microbarom signals (Assink et al., 2014). Simulated and observed microbarom parameters are consistent, as shown by moderate correlation coefficients. In summer, the location of microbarom signals using detections at IS31, KURIS, and MKIAR is found southwest of South America, at a distance larger than $15000 \mathrm{~km}$, near the peri-Antarctic belt where strong ocean storms circulate. This location is consistent with the relatively low amplitude and frequency of the recorded signals.

Further numerical investigations are needed to define the most suitable detection parameters in terms of missed events and the false alarm rate and estimate wave parameter uncertainties accounting for the response functions at all arrays. In this study, the discrepancies between observations and predictions motivate the use of high-resolution detection methods to identify multiple propagation paths from which microbarom energy can reach the array (e.g., Assink et al., 2014). Exploring the capability of high-resolution detection processing techniques to extract multi-directional overlapping coherent energy would be valuable to provide a more realistic picture of the recorded ocean ambient noise (e.g., den Ouden et al., 2020).

For such long propagation ranges, more realistic numerical simulations could reduce the differences between the observed and modeled amplitude; additional studies are thus required to explore time- and range-dependent full-wave propagation techniques while still maintaining computational efficiency (e.g., Waxler and Assink, 2019). Finally, including additional data from other seismo-acoustic networks world- 
ABKAR

(a)

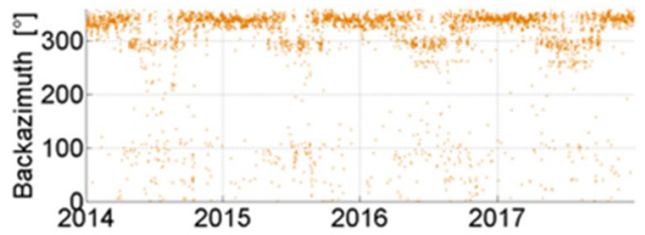

(c)

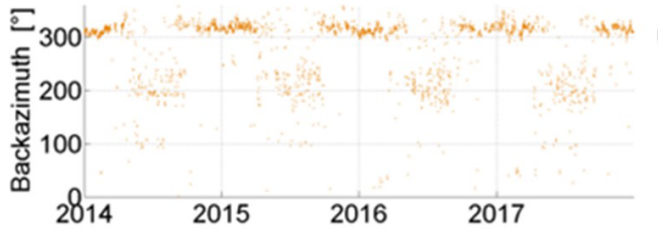

(b)

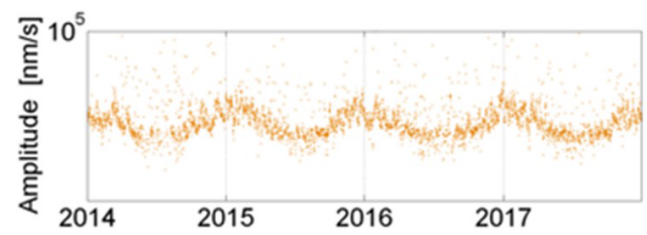

IS31

(d)

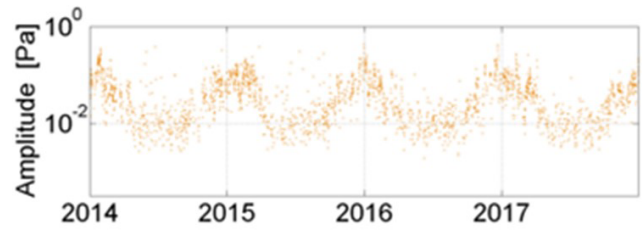

Kurchatov Cross

(e)

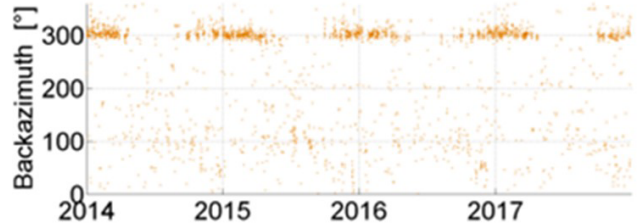

(f)

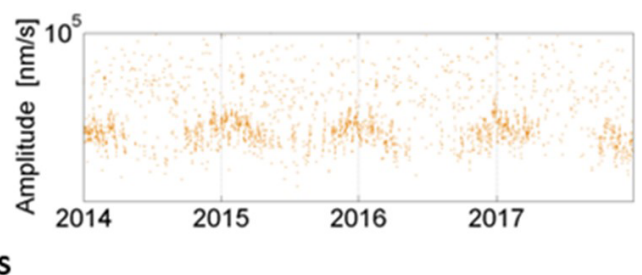

(g)

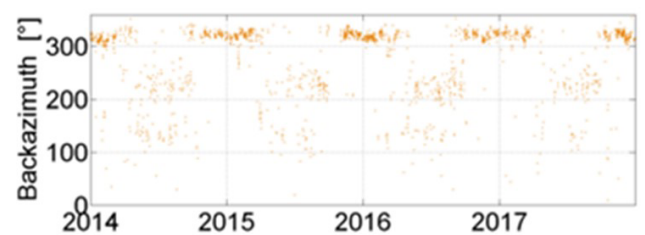

(h)

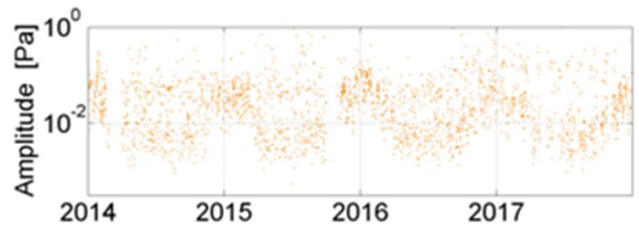

Figure 5. Comparison of the observed back-azimuths and amplitudes at ABKAR (a, b) and IS31 (c, d), $230 \mathrm{~km}$ apart, and collocated Kurchatov Cross $(\mathbf{e}, \mathbf{f})$ and KURIS $(\mathbf{g}, \mathbf{h})$ arrays.

wide would help constrain the microbarom source location, validating long-range propagation modeling, and better characterize station-specific ambient noise signatures, which is important for a successful verification of the CTBT using the IMS. 
Appendix A: Instrument responses

(a)

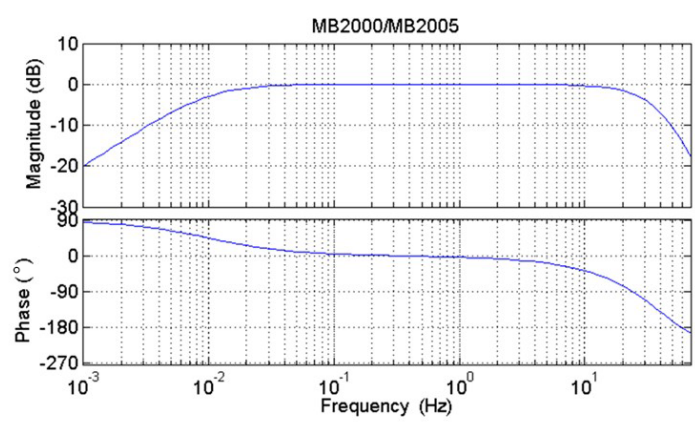

(b)

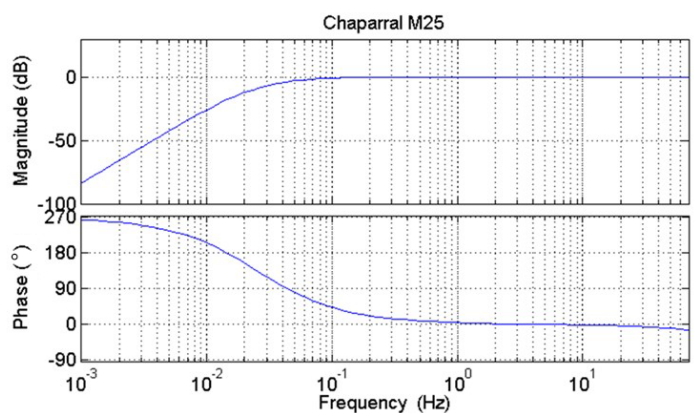

(c)

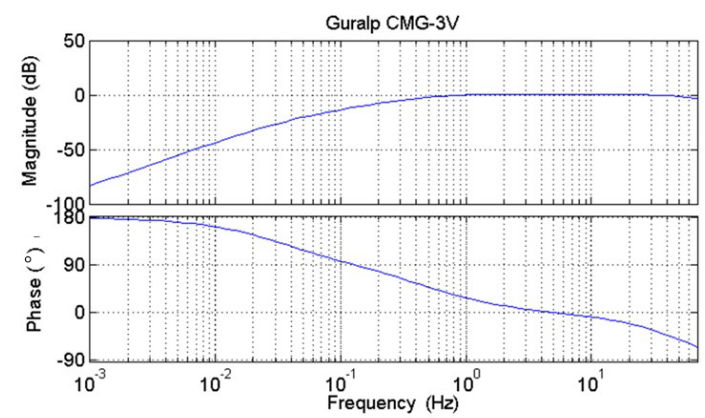

(d)

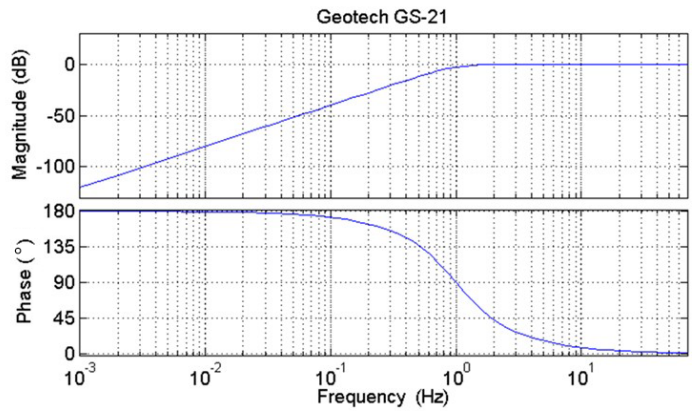

Figure A1. Normalized frequency response of the (a) MB2000 and MB2005, (b) Chaparral M25 microbarometers, (c) Guralp CMG-3V, and (d) Geotech GS-21 seismometers.

Table A1. Description of infrasound and seismic arrays.

\begin{tabular}{llllr}
\hline Array & Sensor & $\begin{array}{l}\text { Response in } \\
\text { units lookup }\end{array}$ & Digitizer & $\begin{array}{r}\text { Sampling } \\
\text { frequency, Hz }\end{array}$ \\
\hline IS31 & MB2000 & $\mathrm{Pa}$ & DASE Aubrac & 20 \\
KURIS & MB2005 & $\mathrm{Pa}$ & Guralp CMG-DM24S6EAM & 20 \\
MKIAR & Chaparral M25 & $\mathrm{Pa}$ & Science Horizons AIM24 & 40 \\
ABKAR, KKAR, MKAR & Geotech GS-21 & $\mathrm{m} \mathrm{s}^{-1}$ & Science Horizons AIM24 & 40 \\
Kurchatov Cross & Guralp CMG 3-V & $\mathrm{m} \mathrm{s}^{-1}$ & Nanometrics Europa-T & 40 \\
\hline
\end{tabular}


Appendix B: Noise spectra

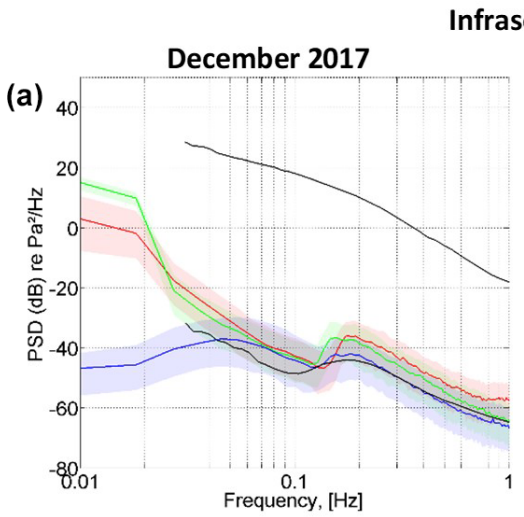

(b)
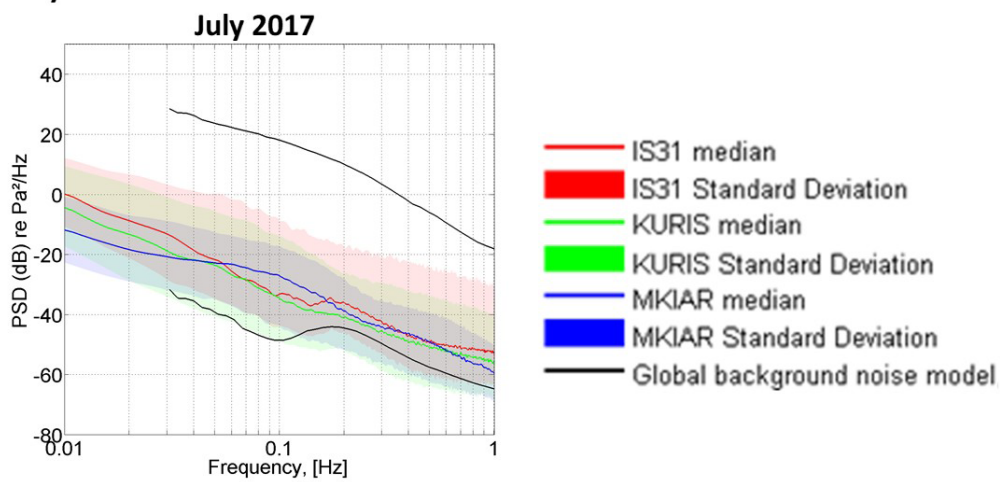

Seismic arrays

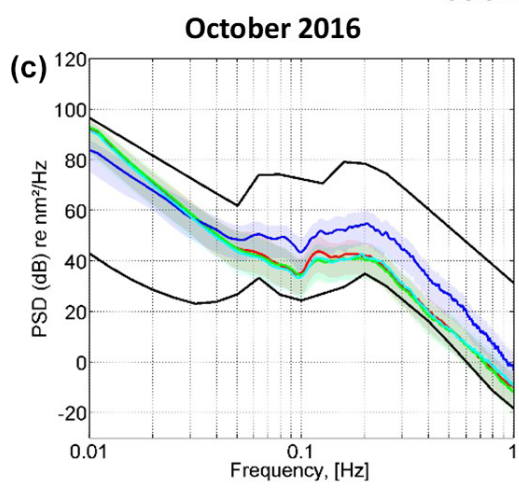

(d)
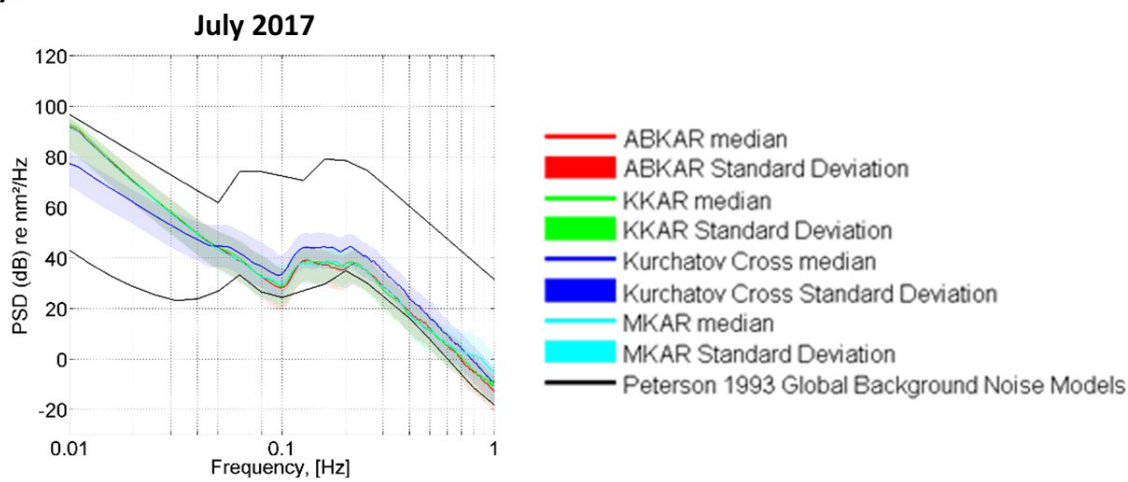

Collocated infrasound and seismic arrays

October 2016

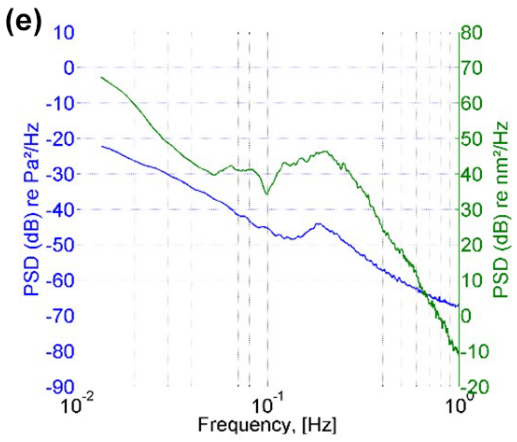

(f)

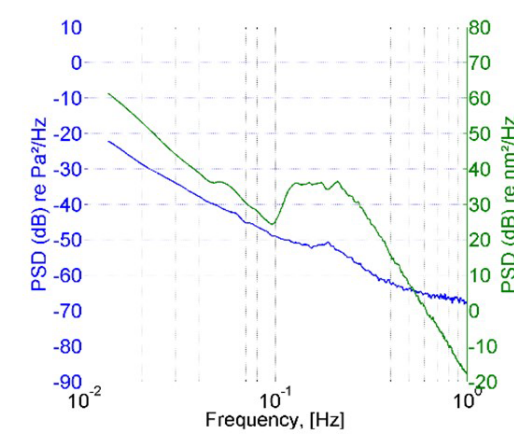

Kurchatov infrasound array

Kurchatov Cross seismic array

Figure B1. PSD noise spectra at infrasound arrays (a, b) and seismic arrays (c, d). Comparison of noise spectra at collocated KURIS and Kurchatov Cross arrays. 
Appendix C: The distribution of the epicenters of the predicted microbarom sources

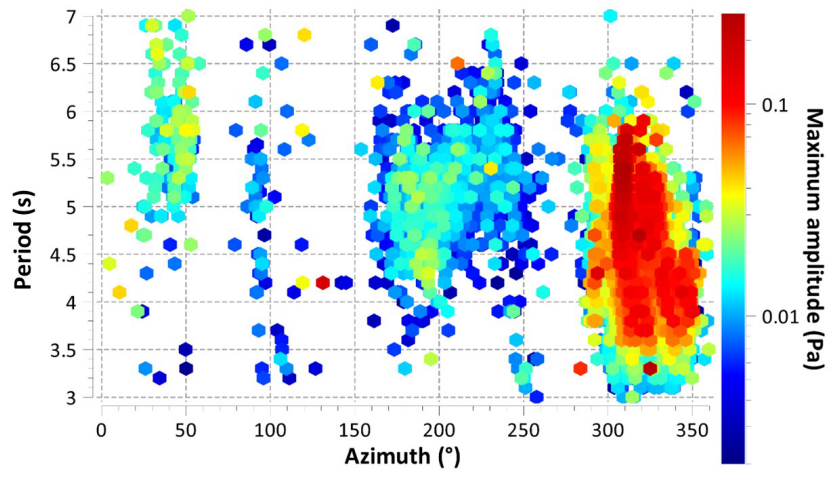

Figure C1. Signal periods versus back-azimuths at IS31 observations in 2017. The amplitude is color coded (in Pa).

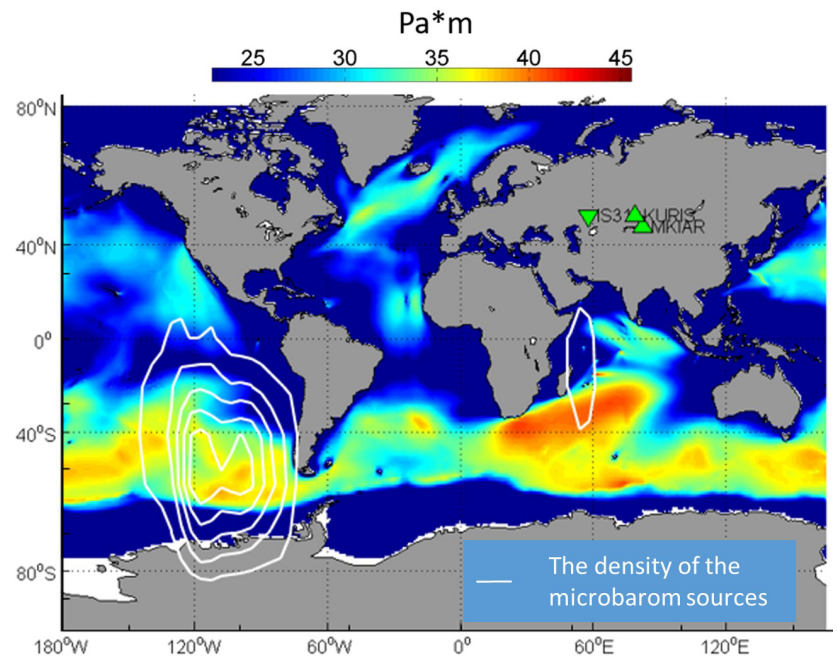

Figure C2. Spatial distribution of the epicenters of microbarom sources in July-August 2017. White contours represent the density of the microbarom source locations obtained via cross-bearing using detections at IS31, KURIS, and MKIAR, during same time periods. At each station, back-azimuths are daily averaged. 
Appendix D: Comparison of back-azimuths at collocated seismic and infrasound arrays

(a)

Entire year 2017

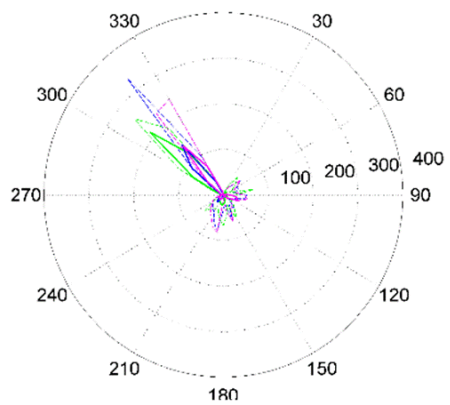

(c)

Summer months 2017

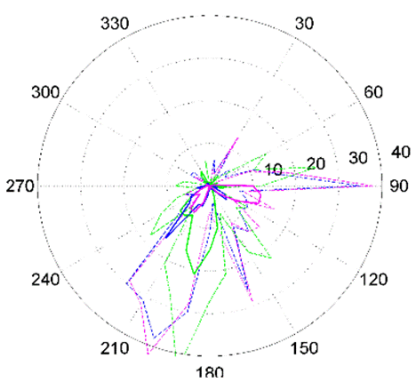

Entire year 2017

(d)

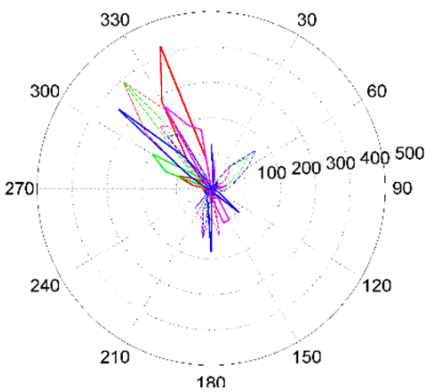

Summer months 2017

(f)

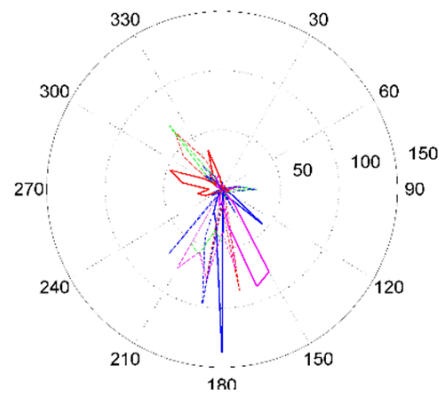

Infrasound arrays

(b)

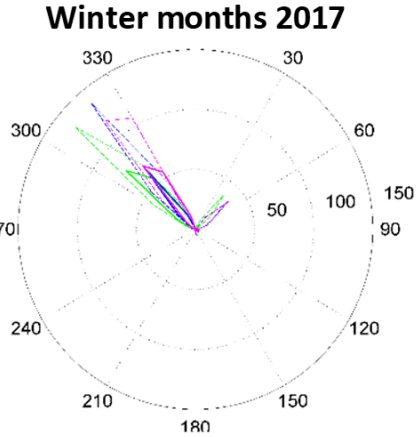

Seismic arrays

(e)

Winter months 2017
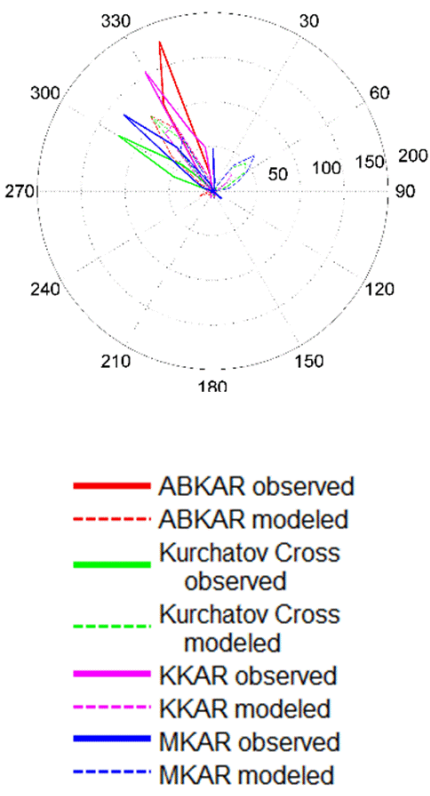

Figure D1. Azimuthal distribution of infrasound detections throughout 2017 (a), from 1 December 2016 to 28 February 2017 (b), and from 1 June to 31 August 2017 (c). Azimuthal distribution of seismic detections throughout 2017 (d), from 1 December 2016 to 28 February 2017 (e), and from 1 June to 31 August 2017 (f). 
Code availability. The code is available by request.

Data availability. Atmospheric wind and temperature profiles are derived from operational high-resolution atmospheric model analysis, defined by the Integrated Forecast System of the ECMWF, available at https://www.ecmwf.int/ (last access: 2 September 2019; ECMWF, 2018). Seismic and infrasound waveforms from the IMS network (https://www.ctbto.org/, last access: 2 September 2019) used in this study are available to the authors, being members of the National Data Centres for the CTBTO. Data of the Kazakhstani national seismic and infrasound arrays are available under request to the Institute of Geophysical Research, National Nuclear Centre of Kazakhstan. Microseism and microbarom detections of the seismoacoustic Kazakh network and microbarom simulations are available at the ISC repository (Smirnov et al., 2020).

Author contributions. NMS and ALP suggested the main outlines of the paper. AS and ALP prepared the historical dataset for processing. MDC and ALP developed the microbarom source model. AS performed microbarom and microseism detections and propagation simulations. AS prepared the paper with contributions from all coauthors. ALP, MDC, and SK made critical reviews and comments to improve the paper.

Competing interests. The authors declare that they have no conflict of interest.

Acknowledgements. This research has been supported by the Commissariat à l'Energie Atomique (CEA, France). The authors also thank Anna Smirnova for support in the manuscript preparation; Jelle Assink, whose comments and suggestions helped improve and clarify the paper; Eleonore Stutzmann for the useful advice on the bathymetry excitation effect; Inna Sokolova and Pavel Martysevich for valuable input on the instrumentation part; and Sven Peter Näsholm and Ekaterina Vorobeva for microbarom model scaling. Massive numerical computations were performed on the S-CAPAD platform of IPGP in France.

Financial support. This research has been supported by the European Research Council (ERC) under the European Union Horizon 2020 Research and Innovation Programme (grant agreement 787399SEISMAZE), the Russian Ministry of Education and Science (grant no. 14.W03.31.0033), and the Russian Foundation for Basic Research (project no. 18-05-00576).

Review statement. This paper was edited by CharLotte Krawczyk and reviewed by Jelle Assink and one anonymous referee.

\section{References}

Ardhuin, F., Stutzmann, E., Schimmel, M., and Mangeney, A.: Ocean wave sources of seismic noise, J. Geophys. Res., 116, C09004, https://doi.org/10.1029/2011jc006952, 2011.

Ardhuin, F., Lavanant, T., and Obrebski, M.: A numerical model for ocean ultra-low frequency noise: wave-generated acousticgravity and Rayleigh modes, J. Acoust. Soc. Am., 134, 3242-3259, https://doi.org/10.1121/1.4818840, 2013a.

Ardhuin, F. and Herbers, T. H. C.: Noise generation in the solid Earth, oceans and atmosphere, from nonlinear interacting surface gravity waves in finite depth, J. Fluid Mech., 716, 316-348, https://doi.org/10.1017/jfm.2012.548, 2013b.

Assink, J. D., Waxler, R., Smets, P., and Evers, L. G.: Bidirectional infrasonic ducts associated with sudden stratospheric warming events, J. Geophys. Res.-Atmos., 119, 1140-1153, https://doi.org/10.1002/2013jd021062, 2014.

Belyashov, A., Dontsov, V., Dubrovin, V., Kunakov, V., and Smirnov, A.: New infrasound array "Kurchatov", NNC RK Bull., 2, 24-30, 2013.

Bertelli, T.: Osservazioni sui piccoli movimenti dei pendoli in relazione ad alcuni fenomeni meteorologiche, Boll. Meteorol. Osserv. Coll. Roma, 9, 1872.

Brekhovskikh, L. M.: Waves in Layered Media, Applied Mathematics and Mechanics, Academic Press, London, UK, https://doi.org/10.1002/zamm.19620420308, 1960.

Cansi, Y.: An automatic seismic event processing for detection and location: The P.M.C.C. Method, Geophys. Res. Lett., 22, 10211024, https://doi.org/10.1029/95g100468, 1995.

Cansi, Y. and Klinger, Y.: An Automated Data Processing Method for Mini-Arrays, Newsl. Eur. Seismol. Cent., 11, 1021-1024, 1997.

Capon, J.: Long-Period Signal Processing Results for LASA, NORSAR and ALPA, Geophys. J. Int., 31, 279-296, https://doi.org/10.1111/j.1365-246x.1972.tb02370.x, 1972.

Ceranna, L., Matoza, R., Hupe, P., Le Pichon, A., and Landès, M.: Systematic array processing of a decade of global IMS infrasound data, in: Infrasound monitoring for atmospheric studies, edited by: Le Pichon, A., Blanc, E., and Hauchecorne, A., Springer, Dordrecht, The Netherlands, 471-484, 2019.

De Carlo, M., Le Pichon, A., Ardhuin, F., and Näsholm, S.: Characterizing and modelling ocean ambient noise using infrasound network and middle atmospheric models, NNC RK Bull., 2, 144151, 2018.

De Carlo, M., Ardhuin, F., and Le Pichon, A.: Atmospheric infrasound generation by ocean waves in finite depth: unified theory and application to radiation patterns, Geophys. J. Int., 21, 569585, https://doi.org/10.1093/gji/ggaa015, 2020.

den Ouden, O., Assink, J. D., Smets, P., Shani-Kadmiel, S., Averbuch, G., and Evers, L.: CLEAN beamforming for the enhanced detection of multiple infrasonic sources, Geophys. J. Int., 221, 305-317, https://doi.org/10.1093/gji/ggaa010, 2020.

Donn, W. L. and Naini, B.: Sea wave origin of microbaroms and microseisms, J. Geophys. Res., 78, 4482-4488, https://doi.org/10.1029/JC078i021p04482, 1973.

Evers, L. G. and Haak, H. W.: Listening to sounds from an exploding meteor and oceanic waves, Geophys. Res. Lett., 28, 41-44, https://doi.org/10.1029/2000gl011859, 2001. 
Evers, L. G. and Siegmund, P.: Infrasonic signature of the 2009 major sudden stratospheric warming, Geophys. Res. Lett., 36, L23808, https://doi.org/10.1029/2009g1041323, 2009.

Garcés, M.: On using ocean swells for continuous infrasonic measurements of winds and temperature in the lower, middle, and upper atmosphere, Geophys. Res. Lett., 31, L19304, https://doi.org/10.1029/2004g1020696, 2004.

Gerstoft, P., Shearer, P. M., Harmon, N., and Zhang, J.: Global P, PP, and PKP wave microseisms observed from distant storms, Geophys. Res. Lett., 35, L23306, https://doi.org/10.1029/2008gl036111, 2008

Gutenberg, B.: Microseisms, microbaroms, storms, and waves in western North America, Eos Trans. AGU, 34, 161-173, https://doi.org/10.1029/TR034i002p00161, 1953.

Hasselmann, K.: A statistical analysis of the generation of microseisms, Rev. Geophys., 1, 177, https://doi.org/10.1029/rg001i002p00177, 1963.

Hasselmann, K.: Feynman diagrams and interaction rules of wave-wave scattering processes, Rev. Geophys., 4, 1, https://doi.org/10.1029/rg004i001p00001, 1966.

Haubrich, R. A. and McCamy, K.: Microseisms: Coastal and pelagic sources, Rev. Geophys., 7, 539, https://doi.org/10.1029/rg007i003p00539, 1969.

Hupe, P., Ceranna, L., Pilger, C., De Carlo, M., Le Pichon, A., Kaifler, B., and Rapp, M.: Assessing middle atmosphere weather models using infrasound detections from microbaroms, Geophys. J. Int., 216, 1761-1767, https://doi.org/10.1093/gji/ggy520, 2018.

IFREMER: Wave Watch 3, available at: ftp://ftp.ifremer.fr/ifremer/ ww3/ (last access: 3 October 2018), 2018.

Kanamori, H. and Given, J. W.: Use of long-period surface waves for rapid determination of earthquake-source parameters, Phys. Earth Planet. Inter., 27, 8-31, https://doi.org/10.1016/00319201(81)90083-2, 1981.

Kedar, S., Longuet-Higgins, M., Webb, F., Graham, N., Clayton, R., and Jones, C.: The origin of deep ocean microseisms in the North Atlantic Ocean, Proc. R. Soc. A, 464, 777-793, https://doi.org/10.1098/rspa.2007.0277, 2008.

KNDC: Observation network of the Institute of Geophysical Research of the National Nuclear Centre of the Republic of Kazakhstan, available at: http://www.kndc.kz/index.php?option= com_content\&view=article\&id=45\&Itemid=147\&lang=en (last access: 3 October 2019), 2019.

Kolínský, P. and Bokelmann, G.: Arrival angles of teleseismic fundamental mode Rayleigh waves across the AlpArray, Geophys. J. Int., 218, 115-144, https://doi.org/10.1093/gji/ggz081, 2019.

Landès, M., Ceranna, L., Le Pichon, A., and Matoza, R. S.: Localization of microbarom sources using the IMS infrasound network, J. Geophys. Res.-Atmos., 117, D06102, https://doi.org/10.1029/2011jd016684, 2012.

Landès, M., Le Pichon, A., Shapiro, N. M., Hillers, G., and Campillo, M.: Explaining global patterns of microbarom observations with wave action models, Geophys. J. Int., 199, 13281337, https://doi.org/10.1093/gji/ggu324, 2014.

Le Pichon, A., Ceranna, L., and Vergoz, J.: Incorporating numerical modeling into estimates of the detection capability of the IMS infrasound network, J. Geophys. Res.-Atmos., 117, D05121, https://doi.org/10.1029/2011jd016670, 2012.
Le Pichon, A., Assink, J. D., Heinrich, P., Blanc, E., CharltonPerez, A., Lee, C. F., Keckhut, P., Hauchecorne, A., Rüfenacht, R., Kämpfer, N., Drob, D. P., Smets, P. S. M., Evers, L. G., Ceranna, L., Pilger, C., Ross, O., and Claud, C.: Comparison of co-located independent ground-based middle atmospheric wind and temperature measurements with numerical weather prediction models, J. Geophys. Res.-Atmos., 120, 8318-8331, https://doi.org/10.1002/2015jd023273, 2015.

Longuet-Higgins, M. S.: A Theory of the origin of microseisms, Philos. T. R. Soc. A, 243, 1-35, https://doi.org/10.1098/rsta.1950.0012, 1950.

Marty, J.: The IMS Infrasound Network: Current Status and Technological Developments, in: Infrasound Monitoring for Atmospheric Studies, edited by: Le Pichon, A., Blanc, E., and Hauchecorne, A., Springer, Cham, 3-62, https://doi.org/10.1007/978-3-319-75140-5, 2019.

Matoza, R. S., Landès, M., Le Pichon, A., Ceranna, L., and Brown, D.: Coherent ambient infrasound recorded by the International Monitoring System, Geophys. Res. Lett., 40, 429-433, https://doi.org/10.1029/2012g1054329, 2013.

Obrebski, M., Ardhuin, F., Stutzmann, E., and Schimmel, M.: Detection of microseismic compressional (P)body waves aided by numerical modelling of oceanic noise sources, J. Geophys. Res.Sol. Ea., 118, 4312-4324, https://doi.org/10.1002/jgrb.50233, 2013.

Olson, J. V. and Szuberla, C. A. L.: Distribution of wave packet sizes in microbarom wave trains observed in Alaska, J. Acoust. Soc. Am., 117, 1032-1037, https://doi.org/10.1121/1.1854651, 2005.

Posmentier, E. S.: A Theory of Microbaroms, Geophys. J. Int., 13, 487-501, https://doi.org/10.1111/j.1365-246x.1967.tb02301.x, 1967.

Shapiro, N. M.: High-Resolution Surface-Wave Tomography from Ambient Seismic Noise, Science, 307, 1615-1618, https://doi.org/10.1126/science.1108339, 2005.

Shapiro, N. M. and Campillo, M.: Emergence of broadband Rayleigh waves from correlations of the ambient seismic noise, Geophys. Res. Lett., 31, L07614, https://doi.org/10.1029/2004gl019491, 2004.

Smets, P. S. M. and Evers, L. G.: The life cycle of a sudden stratospheric warming from infrasonic ambient noise observations, J. Geophys. Res.-Atmos., 119, 84-99, https://doi.org/10.1002/2014jd021905, 2014.

Smirnov, A.: The variety of infrasound sources recorded by Kazakhstani stations, in: CTBT: Science and Technology, Vienna, available at: https://www.ctbto.org/fileadmin/user_upload/ SnT2015/SnT2015_Posters/T2.3-P20.pdf (last access: 27 October 2015), 2015.

Smirnov, A., Dubrovin, V., and Evers, L. G.: Explanation of the nature of coherent low-frequency signal sources recorded by monitoring station network of the NNC RK, NNC RK Bull, 3, 76-81, 2010.

Smirnov, A., De Carlo, M., Le Pichon, A., and Shapiro, N. M.: Signals from severe ocean storms in North Atlantic as it detected in Kazakhstan: observations and modelling, NNC RK Bull., 2, 152-160, 2018.

Smirnov, A., De Carlo, M., Le Pichon, A., Shapiro, N., and Kulichkov, S.: Results of the microseism and microbarom detections by the seismo-acoustic Kazakh network 
and of the microbarom simulation for the infrasound arrays of the network, ISC Seismological Dataset Repository, https://doi.org/10.31905/DSW7L5BV, 2020.

Stehly, L., Campillo, M., and Shapiro, N. M.: A study of the seismic noise from its long-range correlation properties, J. Geophys. Res., 111, B10306, https://doi.org/10.1029/2005jb004237, 2006.

Stutzmann, E., Ardhuin, F., Schimmel, M., Mangeney, A., and Patau, G.: Modelling long-term seismic noise in various environments, Geophys. J. Int., 191, 707-722, https://doi.org/10.1111/j.1365-246x.2012.05638.x, 2012.

Szuberla, C. A. L. and Olson, J. V: Uncertainties associated with parameter estimation in atmospheric infrasound arrays, J. Acoust. Soc. Am., 115, 253-258, https://doi.org/10.1121/1.1635407, 2004.

Toksöz, M. N. and Lacoss, R. T.: Microseisms: mode structure and sources, Science, 159, 872-873, https://doi.org/10.1126/science.159.3817.872, 1968.
WAVEWATCH III Development Group: User manual and system documentation of WAVEWATCH III version 5.16, NOAA/NWS/NCEP/MMAB Technical Note 329, College Park, MD, 326 pp. + Appendices, 2016.

Waxler, R. and Assink, J.: Propagation modeling through realistic atmosphere and benchmarking, in: Infrasound monitoring for atmospheric studies, edited by: Le Pichon, A., Blanc, E., and Hauchecorne, A., Springer, Cham, pringer Nature, Dordrecht, the Netherlands, 509-550, 2019.

Waxler, R. and Gilbert, K. E.: The radiation of atmospheric microbaroms by ocean waves, J. Acoust. Soc. Am., 119, 2651-2664, https://doi.org/10.1121/1.2191607, 2006.

Waxler, R., Gilbert, K., Talmadge, C., and Hetzer, C.: The effects of finite depth of the ocean on microbarom signals, in: 8th International Conference on Theoretical and Computational Acoustics (ICTCA), 2-6 July 2007, Crete, Greece, 2007.

Weaver, R. L.: GEOPHYSICS: Information from Seismic Noise, Science, 307, 1568-1569, https://doi.org/10.1126/science.1109834, 2005. 